\title{
PENENTUAN PARAMETER DAN KURVA SUB INDEKS DALAM PENYUSUNAN INDEKS KUALITAS AIR
}

\section{DETERMINATION OF PARAMETER AND SUB-INDEX CURVES FOR PREPARING WATER QUALITY INDEX}

\author{
Dewi R., Anwar H., Asiah, Retno P. dan Arum P. ${ }^{1}{ }^{2} a s n i^{2)}$ \\ (Diterima tanggal 12-11-2016; Disetujui tanggal 15-12-2016)
}

\begin{abstract}
ABSTRAK
Indeks kualitas air (IKA) digunakan untuk menyederhanakan data kulitas air yang kompleks dalam satu informasi yang mudah dipahami dan berguna untuk publik dan pengambil kebijakan. Tujuan kajian ini adalah untuk menentukan parameter dan kurva sub indeks dalam penyusunan formulasi IKA. Metode yang digunakan dalam penyusunan IKA mengacu pada NSF-WQI. Survei dan pengambilan data dilakukan terhadap 150 panelis yang mempunyai kompetensi di bidang air dan diperoleh 98 panelis yang memberikan respon balik. Dari hasil pengolahan data para panelis diperoleh parameter kualitas air dan pembobotannya serta kurva sub indeks masing-masing parameter. Rata-rata sub indeks masing-masing parameter dibuat kurva sub indeks yang digunakan dalam rumusan IKA. Rumusan IKA diperoleh dengan penjumlahan total hasil perkalian untuk masing-masing bobot parameter dengan nilai sub indeks masing-masing parameter $\left(\mathrm{IKA}=\sum\right.$ wiq $\left.i\right)$. Nilai skor yang diperoleh dari rumusan IKA mempunyai rentang nilai 0 - 100 dan dapat disajikan dalam bentuk klasifikasi air yaitu sangat baik, baik, sedang, dan buruk. Pembagian rentang klasifikasi air tersebut memerlukan proses verifikasi lebih lanjut agar dapat diperoleh hasil yang sesuai.
\end{abstract}

Kata Kunci: Indeks, parameter, kualitas air, panelis, pembobotan, kurva sub indeks

\begin{abstract}
Water quality index (WQI) is used to simplify the complexicity of water quality data in an effective and acceptable information to public and policy makers. The purpose of this study is to determine the parameter and sub index curves in formulating WQI. Method used in WQI formulation refers to the National Sanitary Foundation-Water Quality Index (NSF-WQI). Survey and data collection were conducted on 150 panelists representing the expertise in water quality and 98 panelists provided feedback. Data processing on questionnaires determined the chosen parameters, its weighting and the sub index curves. A weighted mean of sub index from each parameter is combined to create the sub index curve charts. WQI formulation is obtained from the total sum of multiplication of each weighting parameter with its sub index value (WQI $=\sum$ wiqi). Score from WQI formulation has a range of 0-100, and it represents water quality condition which is classified as excellent, good, medium, and bad. The classification requires further verification process in order to obtain the corresponding result.
\end{abstract}

Keyword: Index, parameter, water quality, panelis, weighing, sub-index curve

\section{PENDAHULUAN}

Informasi kualitas air akan menjadi sangat kompleks jika masing-masing parameter kualitas air disampaikan untuk menyatakan kondisi kualitas air yang sebenarnya. Pada umumnya, kondisi kualitas air masih disampaikan secara parsial melalui nilai dari masingmasing parameter yang dipantau. Informasi rinei dengan banyak parameter umumnya hanya berguna untuk pengguna tertentu, namun bagi publik dan pengambil kebijakan

\footnotetext{
1) Puslitbang-Kualitas dan Laboratorium Lingkungan KLHK. Kawasan Puspiptek gedung 210, J1 Raya Puspiptek-Serpong, Tangerang Selatan Banten.
} 
akan susah dipahami. Untuk itu diperlukan suatu indeks yang dapat mengintegrasikan informasi kualitas air tersebut dalam bentuk tunggal dan mudah dimengerti.

Indeks kualitas air memberikan nilai tunggal yang mengekspresikan keseluruhan kualitas air pada lokasi dan waktu tertentu berdasarkan beberapa parameter kualitas air ${ }^{(1,2,3)}$. Indeks ini digunakan untuk menyederhanakan data kualitas air yang kompleks dalam satu informasi yang mudah dipahami dan berguna untuk pengambil kebijakan dalam analisis lingkungan ${ }^{(4)}$. Nilai tunggal dari indeks tersebut tidak bisa menggambarkan keseluruhan kondisi kualitas air karena tidak semua parameter kualitas air dimasukkan dalam indeks tersebut. Oleh karena itu pertimbangan dalam pemilihan parameter kualitas air menjadi proses penting dalam penyusunan IKA. Berdasarkan batasan terhadap parameter penyusunnya tersebut, maka IKA tidak digunakan untuk menilai secara detil kondisi kualitas air di suatu perairan atau kurang sesuai untuk menjawab pertanyaan tentang kualitas air secara spesifik (5). IKA ini digunakan sebagai upaya untuk menjawab pertanyan non teknis tentang kualitas air secara umum. IKA tidak mempunyai unit dan mempunyai kisaran skor dari 0-100 dengan skor yang tinggi menunjukkan kualitas air yang lebih baik ${ }^{(5)}$. IKA dapat memberikan indikasi kesehatan badan air di berbagai titik dan dapat digunakan untuk melacak perubahan dari waktu ke waktu (6,7). IKA juga digunakan sebagai sarana untuk mengevaluasi efektifitas programprogram pengendalian pencemaran air, membantu perumusan kebijakan, membantu dalam mendisain program kualitas air, mempermudah komunikasi dengan publik sehubungan dengan kondisi kualitas air ${ }^{(8)}$.

Penyusunan berbagai IKA pada umumnya meliputi empat tahap yang terdiri dari pemilihan parameter, transformasi parameter dengan satuan yang berbeda dalam skala yang umum, penilaian terhadap bobot tiap parameter dan agregasi sub indeks untuk mendapatkan skor indeks final. Tahapan penyusunan indeks tersebut dapat ditambah atau dikurangi sesuai dengan tujuan penyusunan indeks ${ }^{(1)}$.

Indeks kualitas air pertama kali dikembangkan oleh Horton di Amerika Serikat dengan menggunakan 10 parameter umum kualitas air antara lain DO, pH, coliform, konduktifitas spesifik, alkalinitas, klorida, dan telah diaplikasikan di Eropa, Afrika dan negaranegara Asia ${ }^{(9)}$. Indeks yang serupa dengan Horton kemudian dikembangkan oleh Brown dkk ${ }^{(9)}$. Brown mengembangkan National Sanitation Foundation's Water Quality Index (NSF-WQI) dengan upaya yang lebih besar dan rumit dalam pemilihan parameter, pengembangan skala umum dan penilaian bobot karena dielaborasikan dengan metode Delphy ${ }^{(10)}$. NSF-WQI ini termasuk dalam kategori indeks yang digunakan untuk kualitas air secara umum, lebih komprehensif dan telah dibahas diberbagai makalah ${ }^{(10)}$. NSFWQI menghasilkan 9 (sembilan) parameter terpilih yaitu DO, Fecal coli, pH, BOD, nitrat, fosfat, temperatur, turbiditas dan total padatan dengan pembobotan untuk masing-masing parameter. Nilai indeks yang dihasilkan dari metode NSF-WQI dihitung dengan rumus.

$$
N S F W Q I=\sum_{i=1}^{n} w_{i} I_{i}
$$


IKA menggunakan skala dari nilai 0 sampai 100 untuk memberikan klasifikasi terhadap kualitas air ${ }^{(6)}$. Brown dkk dalam NSF-WQI menentukan lima klasifikasi WQI dalam lima rentang nilai skor yaitu klasifikasi sangat baik (91-100), baik (71-90), sedang (51-70), buruk (26-50), sangat buruk $(0-25)^{(11,12)}$. Kualitas air yang berada pada klasifikasi sangat baik dan baik harus dapat mendukung diversitas kehidupan akuatik yang tinggi . Air tersebut juga cocok untuk segala rekreasi termasuk kegiatan yang memiliki kontak langsung dengan air. Kualitas air yang berada pada klasifikasi sedang umumnya mempunyai diversitas kehidupan akuatik yang lebih sedikit dan lebih sering terjadi peningkatan pertumbuhan alga. Kualitas air yang berada pada klasifikasi kondisi buruk hanya dapat mendukung diversitas kehidupan akuatik yang sangat rendah dan dimungkinkan terjadi pencemaran. Klasifikasi sangat buruk hanya dapat mendukung diversitas kehidupan akuatik yang sangat terbatas atau tertentu dan menerima beban pencemaran yang tinggi ${ }^{(6)}$.

Indeks NSF-WQI merupakan indeks yang paling banyak digunakan dibandingkan dengan indeks lain dan juga dijadikan acuan dalam prosedur penyusunan indeks kualitas air di berbagai negara. IKA digunakan secara luas di berbagai negara untuk memecahkan masalah dalam pengelolaan data dan evaluasi keberhasilan dan kegagalan dalam strategi pengelolaan untuk meningkatkan kualitas air (13).

Kajian ini bertujuan untuk menyusun formulasi Indeks Kualitas Air dengan acuan NSF-WQI. Rumusan IKA digunakan untuk memberikan informasi secara cepat kondisi kualitas air terhadap kebijakan pengelolaan dan pengendalian pencemaran air.

\section{METODOLOGI}

Metode yang digunakan dalam kajian penyusunan formulasi indeks kualitas air sungai ini pada tahap awal adalah melalui studi literatur dan identifikasi formulasi indeks kualitas air yang digunakan oleh beberapa negara. Identifikasi juga dilakukan terhadap tujuan dari penyusunan indeks, jumlah dan jenis parameter serta metode yang digunakan oleh beberapa negara dalam penyusunan indeks kualitas air. Pengumpulan data sekunder terkait dengan hasil pemantauan kualitas air sungai dilakukan untuk melihat parameter-parameter kualitas air yang memberi kontribusi penting terhadap pencemaran lingkungan. Pengumpulan data juga dilakukan melalui diskusi dengan para pakar yang terkait dengan air.

Berdasarkan hasil identifikasi yang telah dilakukan maka penyusunan IKAmenggunakan acuan metode NSF-WQI dengan beberapa penyesuaian. Tahapan dalam penyusunan IKA meliputi penentuan parameter, pembobotan parameter berdasarkan kepentingan terhadap keseluruhan kualitas air, dan penyusunan kurva sub indeks. Pembobotan parameter dan kurva sub indeks disusun dari hasil pengolahan data yang diperoleh dari survei para panelis di bidang air. Langkah awal ditentukan target survei terhadap 150 panelis.

Panelis diminta untuk menyeleksi parameter dengan memberikan bobot pada masingmasing parameter dengan nilai antara 1 (proiritas paling penting) sampai dengan 5 (prioritas paling rendah) (tabel 1). Hasil yang diperoleh dari para panelis dirata-rata untuk menentukan skala prioritas tiap parameter. Hasil rata-rata prioritas dari para panelis juga digunakan untuk menentukan bobot 
Tabel 1. Pembobotan parameter kualitas air.

\begin{tabular}{|c|c|c|c|c|c|c|c|}
\hline \multirow{2}{*}{ No } & \multirow{2}{*}{ Parameter } & \multicolumn{5}{|c|}{ SkalaPembobotan } & \\
\hline & & 1 & 2 & 3 & 4 & 5 & \\
\hline 1 & $\mathrm{pH}$ & & & & & & \\
\hline 2 & $\mathrm{t}^{0} \mathrm{C}$ & & & & & & \\
\hline 3 & TDS & & & & & & \\
\hline 4 & TSS & & & & & & \\
\hline 5 & DO & & & & & & \\
\hline 6 & $\mathrm{BOD}_{5}$ & & & & & & \\
\hline 7 & COD & & & & & & Keterangan Skala Pembobotan: \\
\hline 8 & $\mathrm{NO}_{3}-\mathrm{N}$ & & & & & & Skala 1 : Sangat penting sekali \\
\hline 9 & $\mathrm{NH}_{3}-\mathrm{N}$ & & & & & & Skala 2 : Sangat penting \\
\hline 10 & T-Pospat & & & & & & $\begin{array}{l}\text { Skala } 3 \text { : Penting } \\
\text { Skala } 4 \text { : Kurang penting }\end{array}$ \\
\hline 11 & Fecal Coliforms & & & & & & Skala 5 : Tidak penting \\
\hline
\end{tabular}

tiap parameter dalam sistem penilaian indeks kualitas air.

Penentuan bobot parameter dilakukan dengan menggunakan data rata-rata skala prioritas yang diperoleh dan menghitung bobot sementara. Penghitungan bobot sementara dilakukan dengan menggunakan rumus sebagai berikut:

$$
w_{\text {temp }, i}=\frac{\bar{S}_{\max }}{\bar{S}_{i}}
$$

$$
\begin{gathered}
\text { Keterangan }: w_{\text {temp }, i}=\text { Bobot sementara untuk parameter i } \\
\bar{S}_{\max }=\text { Rata-rata signifikansi tertinggi } \\
\bar{S}_{i} \quad=\text { Rata-rata signifikansi parameter } \mathrm{i}
\end{gathered}
$$

Hasil bobot sementara yang dihasilkan dinormalisasi agar jumlah dari semua parameter bernilai 1. Rumus yang digunakan adalah:

$$
w_{\text {final }, i}=\frac{w_{\text {temp }, i}}{\sum_{i=1}^{n} w_{\text {temp }, i}}
$$

Keterangan $\quad: w_{\text {final }, i}=$ Bobot akhir untuk parameter i
Bobot sementara dihitung dengan membagi rata-rata nilai signifikan tertinggi dengan rata-rata nilai signifikansi setiap parameter. Bobot akhir dihitung dengan cara setiap parameter dibagi dengan jumlah nilai total bobot sementara.

Kurva sub indeks digunakan untuk transformasi unit atau kadar kualitas air yang berbeda dalam bentuk nilai skor yang sama dengan rentang 0-100. Penyusunan kurva sub indeks dilakukan dengan cara meminta kepada masing-masing panelis untuk membuat suatu kurva penilaian untuk setiap parameter dengan sumbu ordinat dicantumkan nilai indeks skala 0-100 dan sumbu absis dicantumkan nilai atau kadar suatu parameter. Kurva yang dibuat oleh panelis menggambarkan indeks dengan nilai parameter tertentu. Dari kurva yang didapat, dilakukan pengolahan data untuk memperoleh kurva sub indeks dari setiap parameter. Kurva sub indeks pada prinsipnya adalah rata-rata aritmatika dari semua kurva yang telah dibuat oleh panelis. Apabila diperlukan, kurva ini dapat diregresi dengan persamaan kurva tertentu, sehingga nilai indeks dapat dihitung 
sebagai fungsi dari suatu nilai parameter tertentu. Kurva tersebut dapat diregresi dengan menggunakan regresi yang sesuai dengan bentuk kurva rata-rata.

\section{HASIL DAN PEMBAHASAN}

Pengambilan data dan survei untuk penyusunan IKA dilakukan melalui wawancara langsung dan pengiriman kuesioner kepada 150 panelis dari berbagai lembaga yang meliputi laboratorium lingkungan, Badan Lingkungan Hidup, Pusat Studi Lingkungan Hidup atau dosen pada perguruan tinggi, serta para pakar atau pemerhati lingkungan hidup. Jumlah panelis yang memberikan respon sebanyak 98 dengan persentase seperti gambar 1 :

Berdasarkan hasil pengolahan data terhadap bobot parameter, maka diperoleh hasil bahwa parameter oksigen terlarut (Dissolved Oxygen/ $D O)$ memiliki nilai tertinggi yaitu 0,14 jika dibandingkan dengan parameter lainnya. Hal ini karena panelis yakin bahwa DO merupakan parameter penting dalam kehidupan organisme air. Sebaliknya, parameter padatan terlarut total (Total Dissolved Solid/ TDS) memiliki nilai pembobotan terkecil, yaitu 0,07 karena TDS hanya menunjukkan jumlah kation dan anion namun tidak menunjukkan tingkat bahaya pencemar terhadap kualitas air (tabel 2).

Dari hasil penyusunan kurva sub indeks diperoleh hubungan kadar masing-masing parameter dengan nilai sub indeks kualitas air dengan rentang 0-100 (Gambar 2). Kurva nilai sub indeks kualitas masing-masing parameter yang terbentuk digunakan sebagai acuan untuk mendapatkan nilai sub indeks kualitas air dengan cara ekstrapolasi ketika kadar parameter pemantauan kualitas air telah dilakukan berdasarkan hasil pengujian di laboratorium.

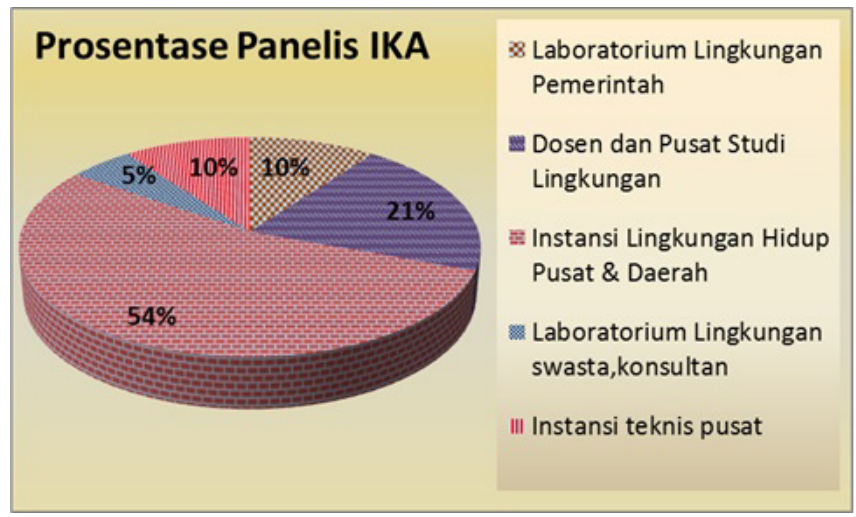

Gambar 1: Persentase panelis yang mengisi kuesioner IKA 
Tabel 2. Pembobotan parameter kualitas air

\begin{tabular}{c|c|c|c|c}
\hline NO & PARAMETER & $\begin{array}{c}\text { RATA-RATA SKALA } \\
\text { PRIORITAS }\end{array}$ & $\begin{array}{c}\text { BOBOT } \\
\text { SEMENTARA }\end{array}$ & $\begin{array}{c}\text { BOBOT } \\
\text { AKHIR }\end{array}$ \\
\hline 1 & DO & 1.27 & 1.00 & 0.14 \\
2 & $\mathrm{pH}$ & 1.48 & 0.86 & 0.12 \\
3 & $\mathrm{COD}$ & 1.56 & 0.82 & 0.11 \\
4 & Fecal coliform & 1.61 & 0.79 & 0.11 \\
5 & BOD & 1.63 & 0.78 & 0.11 \\
6 & NH3-N & 1.96 & 0.65 & 0.09 \\
7 & TSS & 2.97 & 0.65 & 0.09 \\
8 & T-P & 0.57 & 0.08 \\
9 & NO3-N & 0.57 & 0.08 \\
10 & TDS & 0.53 & 0.07 \\
\hline \multicolumn{2}{|c}{ TOTAL } \\
\hline
\end{tabular}
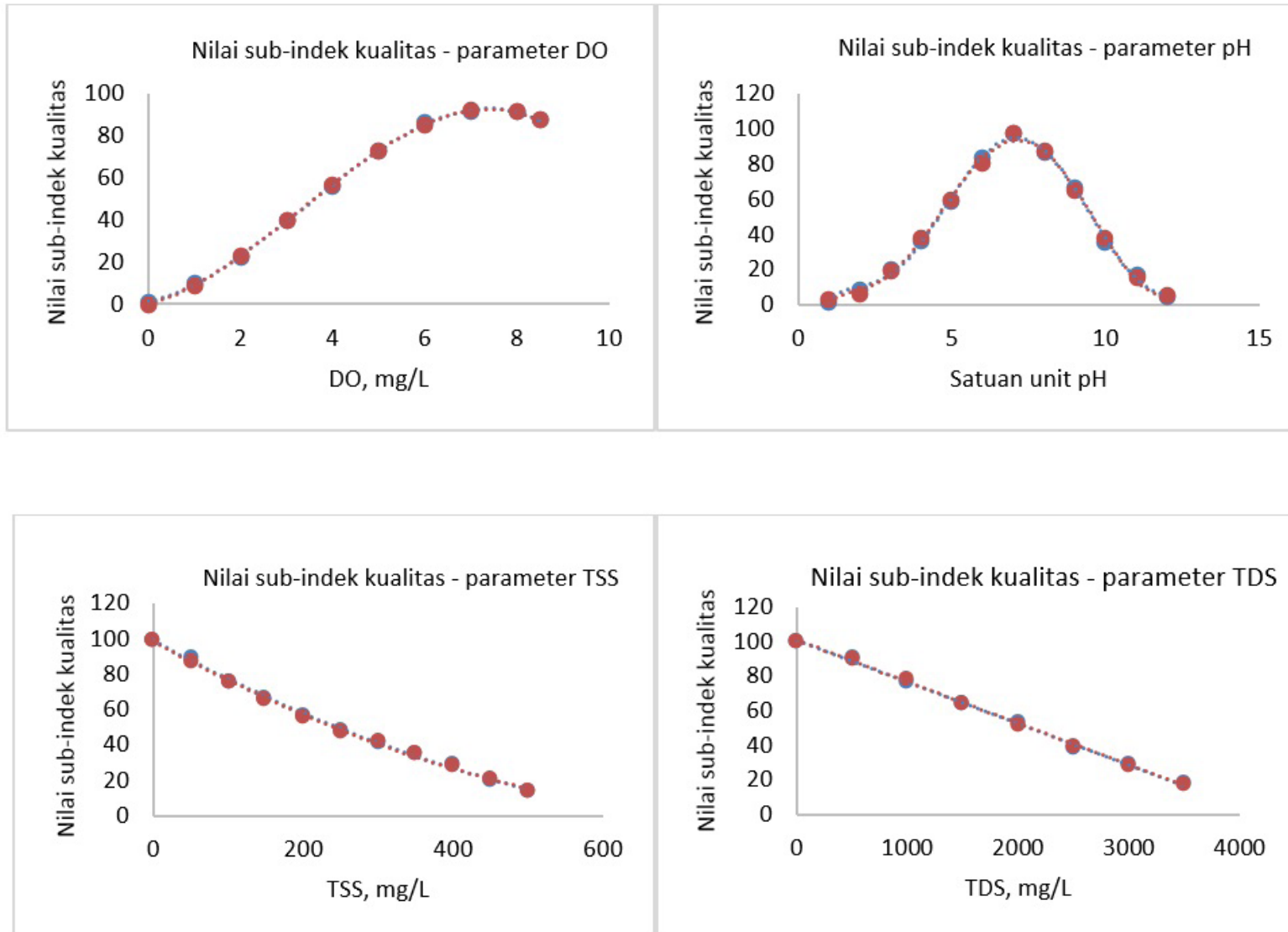

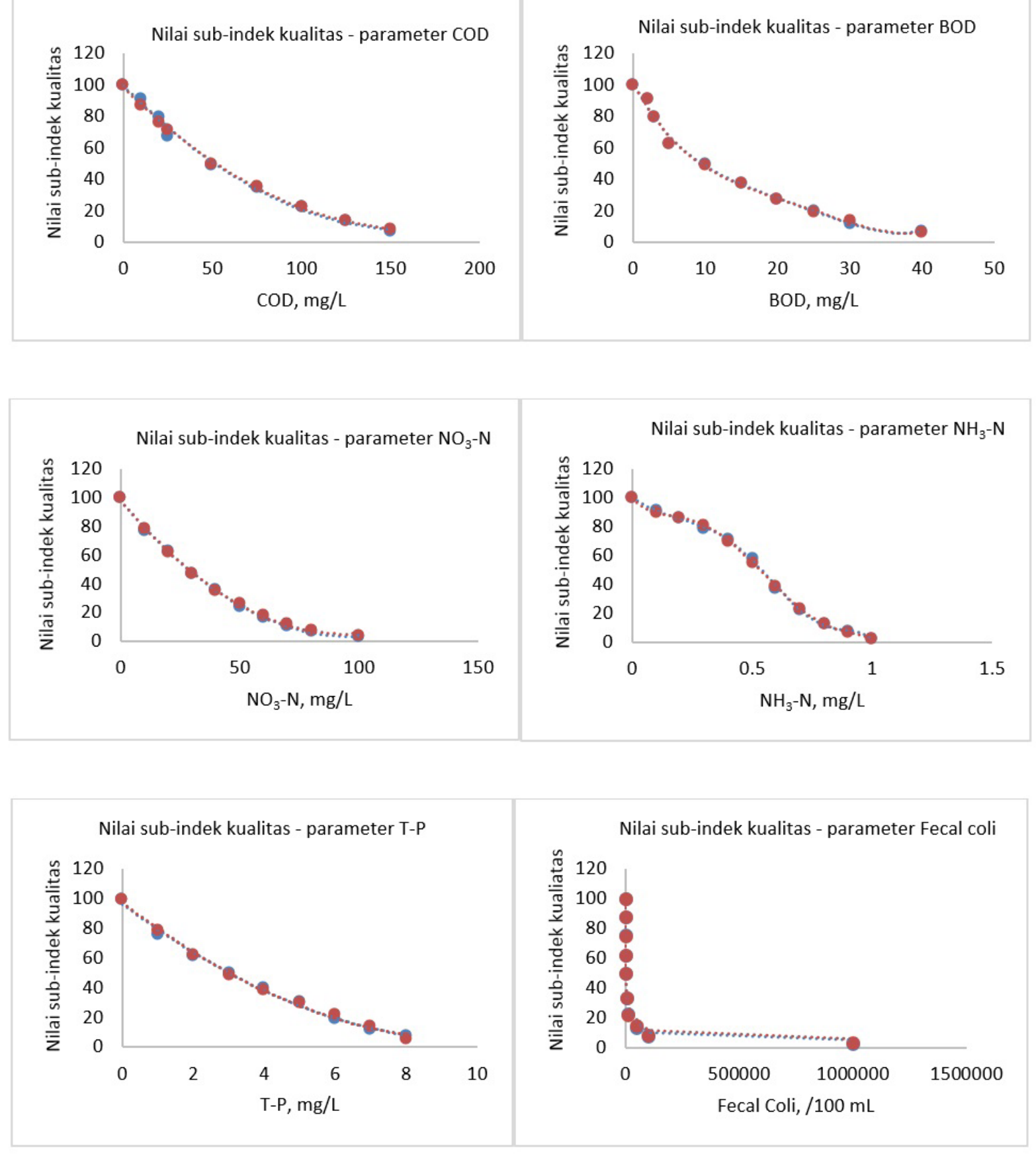

Gambar 2: Kurva sub indeks parameter kualitas air

Selain ekstrapolasi, cara lain untuk mendapatkan nilai sub indeks kualitas air adalah menggunakan persamaan regresi berdasarkan kurva yang terbentuk, sebagaimana Tabel 3. Bila kadar parameter kualitas air telah diperoleh berdasarkan hasil pengujian di laboratorium, maka dengan menggunakan persamaan matematika terkait akan diperoleh sub indeks kualitas air. 
Tabel 3: Persamaan Regresi Kurva Nilai Sub-indek Kualitas Air Tiap Parameter

\begin{tabular}{|c|c|c|c|}
\hline \multirow{2}{*}{ No } & \multirow{2}{*}{ Parameter } & \multicolumn{2}{|c|}{ Persamaan regresi kurva nilai sub-indek kualitas air } \\
\hline & & Persamaan regresi & Koefisien determinasi \\
\hline \multirow{2}{*}{1} & \multirow{2}{*}{ DO } & $Y_{1}=-0.3525 x^{3}+3.5267 x^{2}+5.7687 x$ & $\mathrm{R}^{2}=0.9995$ \\
\hline & & $Y_{2}=-5.1069 x^{2}+76.185 x-191.22$ & $\mathrm{R}^{2}=1$ \\
\hline \multirow{2}{*}{2} & \multirow{2}{*}{$\mathrm{pH}$} & $Y_{1}=-0.5101 x^{3}+7.4939 x^{2}-14.887 x+10.573$ & $\mathrm{R}^{2}=0.9978$ \\
\hline & & $Y_{2}=1.4372 x^{3}-40.947 x^{2}+361.49 x-919.47$ & $\mathrm{R}^{2}=0.9981$ \\
\hline \multirow{2}{*}{3} & \multirow{2}{*}{ COD } & $Y_{1}=-2 E-05 x^{3}+0.0077 x^{2}-1.3838 x+101.52$ & $\mathrm{R}^{2}=0.996$ \\
\hline & & $Y_{2}=0.0027 x^{2}-0.9787 x+93.957$ & $\mathrm{R}^{2}=1$ \\
\hline \multirow{2}{*}{4} & \multirow{2}{*}{$\mathrm{BOD}_{5}$} & $Y_{1}=0.6516 x^{3}-5.5904 x^{2}+4.1489 x+100$ & $\mathrm{R}^{2}=1$ \\
\hline & & $Y_{2}=0.0385 x^{2}-3.3452 x+78.825$ & $\mathrm{R}^{2}=0.999$ \\
\hline \multirow[t]{9}{*}{5} & Fecal Coliforms & $\mathrm{Y}_{1}=-1.2147 \mathrm{x}+100$ & $\mathrm{R}^{2}=1$ \\
\hline & & $Y 2=-0.1377 x+89.23$ & $\mathrm{R}^{2}=1$ \\
\hline & & $Y_{3}=-0.0329 x+78.746$ & $\mathrm{R}^{2}=1$ \\
\hline & & $Y_{4}=-0.0251 x+74.838$ & $\mathrm{R}^{2}=1$ \\
\hline & & $Y_{5}=-0.004 x+53.79$ & $\mathrm{R}^{2}=1$ \\
\hline & & $Y_{6}=-0.0022 x+44.5$ & $\mathrm{R}^{2}=1$ \\
\hline & & $Y_{7}=-0.0002 x+25.015$ & $\mathrm{R}^{2}=1$ \\
\hline & & $Y_{8}=-0.0001 x+18.721$ & $\mathrm{R}^{2}=1$ \\
\hline & & $Y_{9}=-5 E-06 x+8.4622$ & $\mathrm{R}^{2}=1$ \\
\hline \multirow{2}{*}{6} & \multirow{2}{*}{ TSS } & $Y_{1}=-3 E-07 x^{3}+0.0004 x^{2}-0.2766 x+100.64$ & $\mathrm{R}^{2}=0.9992$ \\
\hline & & $Y_{2}=-0.1426 x+84.945$ & $\mathrm{R}^{2}=0.9943$ \\
\hline 7 & $\mathrm{NH}_{3}-\mathrm{N}$ & $Y=-1218 x^{5}+3365.9 x^{4}-3110.5 x^{3}+1042.1 x^{2}-176.82 x+100$ & $\mathrm{R}^{2}=0.9987$ \\
\hline 8 & $\mathrm{NO}_{3}-\mathrm{N}$ & $Y=3 E-07 x^{4}-0.0001 x^{3}+0.0204 x^{2}-2.2971 x+100$ & $\mathrm{R}^{2}=0.9994$ \\
\hline 9 & T-Pospat & $Y=-0.142 x^{3}+2.6418 x^{2}-23.819 x+100$ & $\mathrm{R}^{2}=0.9968$ \\
\hline 10 & TDS & $Y=8 E-10 x^{3}-4 E-06 x^{2}-0.0192 x+100$ & $\mathrm{R}^{2}=0.9994$ \\
\hline
\end{tabular}

Indeks kualitas air dapat dihitung bila kadar parameter pemantauan kualitas air khususnya $\mathrm{DO}, \mathrm{pH}, \mathrm{COD}$, Fecal coliform, $\mathrm{BOD}_{5}, \mathrm{NH}_{3}-\mathrm{N}$, TSS, T-Phospat, $\mathrm{NO}_{3}$-N dan TDS dimasukkan ke dalam persamaan regresi dan dikalikan dengan faktor pembobot untuk masing-masing parameter terkait. Total indeks kualitas air yang diperoleh dapat diklasifikasikan berdasarkan rentang sesuai National Sanitation Foundation (NSF) yaitu rentang skor 91-100 klasifikasi sangat baik, rentang 71-90 klasifikasi baik, rentang 51-70 klasifikasi sedang, rentang 26-50 klasifikasi buruk dan rentang 0-25 klasifikasi sangat buruk. Tabel 4 memberikan contoh perhitungan status indeks kualitas air untuk Kriteria Mutu Air (KMA) kelas I berdasarkan Peraturan Pemerintah Republik Indonesia Nomor 82 tahun 2001 tentang Pengelolaan Kualitas Air dan Pengendalian Pencemaran Air (PP 82/2001) ${ }^{(14) . ~ S e h u b u n g a n ~}$ dengan hasil perhitungan indeks kualitas air diperoleh nilai 83,80, maka kualitas air dikategorikan baik berdasarkan klasifikasi NSF.

Bila kriteria mutu air kelas I berdasarkan PP 82/2001 memberikan nilai kualitas air "BAIK" bukan "SANGAT BAIK", maka klasifikasi berdasarkan NSF perlu dipertimbangkan untuk penerapannya di Indonesia. Sehubungan dengan hal tersebut, penyesuaian rentang 
Tabel 4: Perhitungan IKA menggunakan nilai parameter dalam KMA kelas I PP 82/2001

\begin{tabular}{|c|c|c|c|c|c|}
\hline Parameter & $\begin{array}{l}\text { Nilai parameter kualitas air } \\
\text { KMA kelas I PP82/2001 }\end{array}$ & Satuan & $\begin{array}{l}\text { Nilai Sub- } \\
\text { indek }\end{array}$ & Faktor Pembobot & Sub Total \\
\hline DO & 6 & $\mathrm{mg} / \mathrm{L}$ & 85.43 & 0.14 & 11.66 \\
\hline $\mathrm{pH}$ & 7 & - & 97.52 & 0.12 & 11.52 \\
\hline COD & 10 & $\mathrm{mg} / \mathrm{L}$ & 87.66 & 0.11 & 9.84 \\
\hline Fecal coliform & 100 & MPN/100 mL & 75.46 & 0.11 & 8.29 \\
\hline $\mathrm{BOD}_{5}$ & 2 & $\mathrm{mg} / \mathrm{L}$ & 91.15 & 0.11 & 9.82 \\
\hline $\mathrm{NH}_{3}-\mathrm{N}$ & 0.5 & $\mathrm{mg} / \mathrm{L}$ & 55.61 & 0.09 & 5.05 \\
\hline TSS & 50 & $\mathrm{mg} / \mathrm{L}$ & 87.33 & 0.09 & 7.88 \\
\hline T-Pospat & 0.2 & $\mathrm{mg} / \mathrm{L}$ & 95.34 & 0.08 & 7.67 \\
\hline $\mathrm{NO}_{3}-\mathrm{N}$ & 10 & $\mathrm{mg} / \mathrm{L}$ & 78.97 & 0.08 & 6.33 \\
\hline TDS & 1000 & $\mathrm{mg} / \mathrm{L}$ & 78 & 0.07 & 5.72 \\
\hline & & & TOTAL $=$ & 1.00 & 83.80 \\
\hline & & & \multicolumn{2}{|c|}{ Indek Kualitas Air = } & 83.80 \\
\hline & & & \multicolumn{2}{|c|}{ Klasifikasi Kualitas Air $=$} & BAIK \\
\hline
\end{tabular}

klarifikasi perlu didiskusikan lebih lanjut dengan para pakar kualitas air untuk penyesuaiannya.

\section{SIMPULAN}

Parameter yang dihasilkan untuk penyusunan IKA yaitu $\mathrm{pH}, \mathrm{DO}, \mathrm{BOD}, \mathrm{COD}, \mathrm{TDS}, \mathrm{TSS}$, $\mathrm{NH}_{3}, \mathrm{NO}_{3}$, TP dan Fecal coli. Pemilihan dan pembobotan parameter serta penentuan kurva sub indeks dalam penyusunan IKA dapat mengacu pada metode yang dilakukan oleh NSF-WQI, namun klasifikasi hasil yang dikeluarkan oleh NSF-WQI tidak bisa langsung digunakan untuk hasil rumusan IKA yang telah tersusun. Perlu dilakukan verifikasi dalam penetapan klasifikasi hasil dengan menggunakan data primer yang valid serta konsesus para pakar air. Rumusan IKA dapat dikembangkan lebih spesifik berdasarkan karakteristik masing-masing wilayah.

\section{UCAPAN TERIMA KASIH}

Ucapan terima kasih disampaikan kepada para narasumber, panelis yang terlibat baik dari perguruan tinggi, instansi lingkungan hidup pusat, provinsi dan kabupaten/kota, laboratorium pemerintah atau swasta dan peneliti, konsultan serta berbagai pihak yang telah berpartisipasi dan mendukung terlaksananya kajian ini.

\section{DAFTAR PUSTAKA}

(1) Abbasi, T., \& Abbasi. (2012). Water quality Indices' Approach to WQI Formulation.

(2) Yogendraa, K., \& Puttaiah, ET., (2008).Determination of water quality Index and Sustability of an Urban waterbody in Shimoga Town, Karnataka. Proceedings of Taal2007: The 12" World lake Conference:342-346

(3) Semiromi, F., Babaei, A. H., Hassani, A., Torabian, A. R., Karbassi \& Lotfi, F.H. (2011). 'Evolution of a New Surface Water Quality Index for Karoon Catchment in Iran', Water Science \& Technology, 64 (12), 24832491

(4) Juand DG, Luis F Carvajal, Francisco MT (2012). Water Quality Index based on Fuzzy logic Applied to the 
Aburra River basin in the Jurisdiction of the metropolitan Area. 2011. Nro 171,pp 50-58. Medellin.ISSN 00127353.

(5) Semiromi, F., Babaei, A. H., Hassani, A., Torabian, A. R., Karbassi \& Lotfi, F.H.(2011). 'Water Quality Index Development Using Fuzzy Logic: A case study of the Karoon River of Iran. African Journal of Biotechnology Vol 10(50)

(6) Water quality Index protocol. The PathFinder Science network. Diakses dari: http://www.pathfindersscience. net/stream/cproto4.cfm

(7) Srivastava, G. , Kumar, P., (2013). Water Quality Index with Missing Parameters. International Journal of research in Engineering and Technology. Volume 02 Issue :4. ISSN 2319-1163.

(8) Kementerian Lingkungan Hidup dan Kehutanan. (2014). Indeks Kualits Lingkungan Hidup 2013. Jakarta.

(9) Shweta,T et al. (2013). Water Quality Assessment in Terms of Water Quality Index. American Journal of Water Resources 1.3
(10) Poonam, T., et al. (2015). Water Quality Indices-Important Tools for Water Quality Assessment: A Review. International Journal of Advances in chemistry

(11) National Sanitation Foundation Water quality index. http:/bcn.boulder. co.us/basin/watershed/wqi_nsf.html. diakses 2 Oktober 2013

(12) Goverment of Newfoundland dan Labrador, Dept of Environment and Concervation. Calculation of Drinking Water Quality Index.

(13) Vaheedunnisha, \& Shukla, S.K., (2013). Water quality Assesment of RoopSagarPond of Satna using NSF-WQI. International Journal of Innovative research in Science, engineering and technology. Vol 2 ISSN 2319-8753.

(14) Kementerian Negara Lingkungan Hidup. (2001). Peraturan Pemerintah no 82 tahun 2001 tentang Pengelolaan Kualitas Air dan Pengendalian Pencemaran Air, Jakarta. 